\title{
Epidemiological investigation of porcine circovirus type 2 and its coinfection rate in Shandong province in China from 2015 to 2018
}

Zicheng Ma', Mengda Liu², Zhaohu Liu' , Fanliang Meng ${ }^{1}$, Hongyu Wang ${ }^{1}$, Longlong Cao', Yan Li', Qiulin Jiao ${ }^{1}$, Zifeng $\operatorname{Han}^{3^{*}}$ and Sidang Liu ${ }^{1 *}$ (D)

\begin{abstract}
Background: Porcine circovirus type 2 (PCV2) is one of the crucial swine viral pathogens, caused porcine circovirus associated diseases (PCVAD). Shandong province is one of the most important pork producing areas and bears a considerable economic loss due to PCVAD. However, there is limited information on epidemiology and coinfection rate of PCV2 with other critical swine diseases in this area, such as porcine reproductive and respiratory syndrome virus (PRRSV), classical swine fever virus (CSFV), Pseudorabies virus (PRV), and porcine epidemic diarrhea virus (PEDV).

Results: Overall, 89.59\% serum samples and 36.98\% tissue samples were positive for PCV2 specified ELISA and PCR positive for PCV2, respectively. The coinfection rates of PCV2 with PRRSV, PRV, CSFV, and PEDV were 26.73\%, 18.37\%, $13.06 \%$, and $3.47 \%$, respectively. Moreover, genetic characteristic of PCV2 were analyzed based on the cap genes showing that PCV2d is the dominant sub-genotype circulating in the province.

Conclusions: Our findings reveal that PCV2d, as the dominant strain, is prevailing in pig farms in Shandong province at high levels. There was a high frequency of coinfection of PCV2 and PRRSV.
\end{abstract}

Keywords: Porcine circovirus, Veterinary epidemiology, Coinfection, Phylogenetic analysis, Shandong province

\section{Background}

Porcine Circoviruses (PCVs) are single-standard circular DNA virus, which belong to the member of genus Circovirus within the family of Circoviridae [1]. PCVs includes PCV1, PCV2, and PCV3. PCV1 was initially found in a contaminant of porcine kidney 15 cells in 1974, known as non-pathogenic [2]. Unlike PCV1, PCV2 can cause various clinical signs, such as postweaning multisystemic

\footnotetext{
*Correspondence: alex_hzf@hotmail.com; liusid@sdau.edu.cn

${ }^{3}$ Emergency Centre for the Control of Transboundary Animal Diseases, Food and Agriculture Organization of the United Nations (FAO), 100600 Beijing, China

${ }^{1}$ College of Animal Science and Veterinary Medicine, Shandong Agricultural University, 271018 Taian, China

Full list of author information is available at the end of the article
}

wasting syndrome (PMWS), porcine dermatitis and nephropathy syndrome (PDNS), enteritic disease, and reproductive failure in breeding pigs [3]. PCV2 has been recognized as an economically important swine pathogen that threaten the global swine industry.

As one of the smallest animal viruses, PCV2 has a closed single-stranded DNA genome of 1766-1769 nucleotides with no envelope [4]. The genome contains 11 open reading frames (ORFs), of which four ORFs were well-characterized [5, 6]. PCV2 ORF1 and ORF2 encode replicase (Rep) and capsid (Cap) protein that are of great importance for virus entry and its replication $[7,8]$. It was reported that ORF2 gene shows more genetic variations compared to ORF1, which is commonly used as a

(c) The Author(s). 2021 Open Access This article is licensed under a Creative Commons Attribution 4.0 International License, which permits use, sharing, adaptation, distribution and reproduction in any medium or format, as long as you give appropriate credit to the original author(s) and the source, provide a link to the Creative Commons licence, and indicate if changes were made. The images or other third party material in this article are included in the article's Creative Commons licence, unless indicated otherwise in a credit line to the material. If material is not included in the article's Creative Commons licence and your intended use is not permitted by statutory regulation or exceeds the permitted use, you will need to obtain permission directly from the copyright holder. To view a copy of this licence, visit http://creativecommons.org/licenses/by/4.0/ The Creative Commons Public Domain Dedication waiver (http://creativecommons.org/publicdomain/zero/1.0/) applies to the data made available in this article, unless otherwise stated in a credit line to the data. 
Table 1 Seroprevalence rate of PCV2 and S/P ratios in different herds in Shandong Province from 2015 to 2018

\begin{tabular}{|c|c|c|c|c|c|c|c|c|}
\hline \multirow[t]{2}{*}{ Year } & \multirow{2}{*}{$\begin{array}{l}\text { Number } \\
\text { of } \\
\text { samples }\end{array}$} & \multirow{2}{*}{$\begin{array}{l}\text { Number } \\
\text { of } \\
\text { positive } \\
\text { samples }\end{array}$} & \multirow[t]{2}{*}{ SPR } & \multicolumn{5}{|c|}{ Different Herds } \\
\hline & & & & Sows & $\begin{array}{l}\text { Replacement } \\
\text { pigs }\end{array}$ & Boars & $\begin{array}{l}\text { Young piglets } \\
(<100 \text { d) }\end{array}$ & $\begin{array}{l}\text { Fattening pigs } \\
(>100 \mathrm{~d})\end{array}$ \\
\hline 2015 & 1257 & 1097 & $87.27 \%$ & $1.78 \pm 0.04$ & $1.79 \pm 0.03$ & $1.48 \pm 0.01$ & $0.97 \pm 0.02$ & $1.51 \pm 0.07$ \\
\hline 2016 & 1850 & 1642 & $88.76 \%$ & $1.80 \pm 0.02$ & $1.43 \pm 0.02$ & $1.66 \pm 0.02$ & $1.01 \pm 0.01$ & $1.81 \pm 0.05$ \\
\hline 2017 & 2121 & 1895 & $89.34 \%$ & $1.74 \pm 0.02$ & $1.61 \pm 0.02$ & $1.72 \pm 0.03$ & $1.03 \pm 0.02$ & $1.66 \pm 0.04$ \\
\hline 2018 & 1758 & 1625 & $92.43 \%$ & $1.56 \pm 0.01$ & $1.47 \pm 0.03$ & $1.41 \pm 0.01$ & $0.91 \pm 0.03$ & $1.43 \pm 0.03$ \\
\hline Total & 6986 & 6259 & $89.59 \%$ & $1.77 \pm 0.01$ & $1.70 \pm 0.02$ & $1.68 \pm 0.01$ & $1.01 \pm 0.02$ & $1.55 \pm 0.03$ \\
\hline
\end{tabular}

phylogenetic and epidemiological marker [9]. The evolution of PCV2 was resulted from genetic mutations and combination, which leads to the generation of genetic diversity. Genotypic shifts may be relevant to changes in pathogenicity and vaccine immunity. The European Consortium on PCV disease proposed pairwise sequence comparisons and linearized phylogenetic trees in 2008, which classified PCV2 strains into three genotypes, including PCV2a, PCV2b, and PCV2c [10]. The PCV2d genotype was firstly report in 2010 [11], and it has been identified as a predominant genotype in numerous countries [12-16].

Co-infection of viruses plays a critically important role in animal disease management and control in the field $[14,17]$. Besides of PCVs, there are other viral pathogens threatening the pig raising industry at regional, national and global level, including porcine epidemic diarrhea virus (PEDV), porcine reproductive and respiratory syndrome virus (PRRSV), pseudorabies virus (PRV), classical swine fever virus (CSFV). Previous investigation has shown that PCV2 pathogenesis can be exacerbated by a coinfection with an additional swine viral disease, such as PRRSV and PEDV $[18,19]$.

Shandong province, as one of the most essential regions in China, which raises dense pig population. It was estimated that there were 28 million pigs and 3 million sows produced in Shandong province in 2017. However, there is lack of information on PCV2 prevalence and its coinfection with other crucial swine viral diseases in intensive pig farms in Shandong. The goal of this study was to elucidate the epidemiological and evolutionary dynamics of PCV2, as well as its coinfection rates in Shandong province from 2015 to 2018.

\section{Results}

Seroprevalence Rate (SPR) of PCV2

Serum PCV2 antibodies were tested by ELISA in different herds from 2015 to 2018. Consistent with previous studies in other provinces of China [20, 21], the overall SPR of PCV2 was shown as approximately $90 \%$ in the studied pig farms in the province, as described in Table 1. SPR of PCV2 was gradually increased from the bottom year in 2015 (87.27\%) to the highest level (92.43\%) in 2018. Moreover, the lowest average S/P ratio (1.01) was found in young piglets ranging from 0.91 to 1.03. The average $S / P$ ratio of fattening pigs was 1.55 with the highest (1.81) in 2016 and the lowest (1.43) in 2018. The remaining three herds showed an averaging $\mathrm{S} / \mathrm{P}$ ratio at approximately 1.72 .

\section{PCR positive rate of $\mathrm{PCV} 2$}

All 1,325 tissue samples from Shandong province were tested by PCR, of which 490 samples were shown as positive of PCV2. The results of positive rate of PCV2 were shown in different years (Table 2). The overall average positive rate of PCV2 reached 36.98\% during the investigation period, with the highest rate (43.21\%) observed in 2017 (191/442) and lowest (31.16\%) in $2016(91 / 292)$.

\section{Phylogenetic analysis of PCV2}

Recent studies have indicated a new genotype shifting from PCV2b to PCV2d in various regions in China [15,

Table 2 The positive rate of PCV2 DNA from 2015 to 2018

\begin{tabular}{llll}
\hline Year & Number of samples & Number of positive samples & Positive rate \\
\hline 2015 & 140 & 56 & $40.00 \%$ \\
2016 & 292 & 91 & $31.16 \%$ \\
2017 & 442 & 191 & $43.21 \%$ \\
2018 & 451 & 152 & $33.70 \%$ \\
Total & 1325 & 490 & $36.98 \%$ \\
\hline
\end{tabular}


22-24], indicating that PCV2d has become a dominant genotype. In order to understand current dominant strain and genotype in this field, a phylogenetic tree was developed based on ORF2 sequences of 32 PCV2 gained in 2018 and 18 ORF2 from PCV2 reference strains deposited in GenBank database. Table 3 summarizes the geographic distribution, genotype, tissue, and GenBank accession number of the investigated PCV2 strains.

Table 3 Information of positive samples and GenBank accession number of PCV2-Cap genes

\begin{tabular}{|c|c|c|c|c|}
\hline No. & City & Genotype & Tissue & $\begin{array}{l}\text { Genbank } \\
\text { accession number }\end{array}$ \\
\hline 1 & Liaocheng & PCV2d & lymph & MK545025 \\
\hline 2 & Tai'an & PCV2d & lymph & MK545026 \\
\hline 3 & Qingdao & PCV2d & lymph & MK545027 \\
\hline 4 & Laiwu & PCV2d & lymph & MK545028 \\
\hline 5 & Dongying & PCV2d & lymph & MK545029 \\
\hline 6 & Tai'an & PCV2d & lymph & MK545030 \\
\hline \multirow[t]{5}{*}{7} & Binzhou & PCV2d & lymph & MK545031 \\
\hline & Yantai & PCV2d & spleen & \\
\hline & Ji'nan & PCV2d & lymph & \\
\hline & Rizhao & PCV2d & spleen & \\
\hline & Ji'nan & PCV2d & lymph/spleen & \\
\hline 8 & Jining & PCV2d & lymph & MK545032 \\
\hline 9 & Dongying & PCV2d & lymph & MK545033 \\
\hline 10 & Rizhao & PCV2d & lymph & MK545034 \\
\hline \multirow[t]{3}{*}{11} & Ji'nan & PCV2d & lymph & MK545035 \\
\hline & Weifang & PCV2d & lymph & \\
\hline & Ji'nan & PCV2d & lymph/spleen & \\
\hline 12 & Zaozhuang & PCV2d & lymph & MK545036 \\
\hline 13 & Jinan & PCV2d & lymph & MK545037 \\
\hline 14 & Tai'an & PCV2d & spleen & MK545038 \\
\hline 15 & Liaocheng & PCV2d & spleen & MK545039 \\
\hline 16 & Liaocheng & PCV2d & lymph/spleen & MK545040 \\
\hline 17 & Heze & PCV2d & lymph & MK545041 \\
\hline \multirow[t]{2}{*}{18} & Tai'an & PCV2d & lymph & MK545042 \\
\hline & Heze & PCV2d & lymph & \\
\hline 19 & Ji'nan & PCV2d & lymph & MK545043 \\
\hline 20 & Dongying & PCV2d & lymph & MK545044 \\
\hline 21 & Weifang & PCV2d & lymph & MK545045 \\
\hline 22 & Ji'nan & PCV2d & lung & MK545046 \\
\hline 23 & Liaocheng & PCV2d & lymph & MK545047 \\
\hline 24 & Tai'an & PCV2d & lymph & MK545048 \\
\hline 25 & Binzhou & PCV2d & lymph/spleen & MK545049 \\
\hline 26 & Weihai & PCV2d & lymph & MK545050 \\
\hline 27 & Liaocheng & PCV2d & lymph & MK545051 \\
\hline 28 & Zaozhuang & PCV2d & spleen & MK545052 \\
\hline 29 & Heze & PCV2d & lymph & MK545053 \\
\hline 30 & Tai'an & PCV2d & lymph & MK545054 \\
\hline 31 & Liaocheng & PCV2d & lymph/spleen & MK545055 \\
\hline 32 & Liaocheng & PCV2d & lymph & MK545056 \\
\hline
\end{tabular}


Interestingly, all 32 ORF2 sequences were clustered with PCV2d isolates (Fig. 1).

\section{Co-infection rate}

All PCV2-PCR positive samples were measured for the co-infection status of PRRSV, CSFV, PRV and PEDV. They were demonstrated depending on areas (Table 4). In our study, $26.73 \%$ of PCV2 positive pigs were found to be co-infected by PRRSV, followed with $18.37 \%$ (90/ 490) by PRV. The coinfection by PCV2 and CSFV was 13.06\% (64/490). The positive rate of PCV2 and PEDV coinfection was $3.47 \%(17 / 490)$. The co-infection rates of PRV and PCV2 were over 18.37\% (90/490) with the highest in Tai'an (28/90), followed by Linyi (15/90) Ji'ning (11/90), and Liaocheng (10/90).

\section{Sequence alignment of cap protein}

The multiple alignments of PCV2 Cap protein were carried out by a Clustal W method to evaluate the amino acid mutations of Cap protein. Consistent with previous studies [11], typical motif 86TNKISI91 was found in result of the PCV2 Cap alignment analysis. Moreover, other typical motifs 129FFPKST134 and 185MRIQTSK192 were observed in PCV2d strains. In addition, other amino acid substitutions at different sites were summarized in Fig. 2.

\section{Discussion}

Since 1990s, PCV2 has been considering as one of the essential viral pathogen of pigs globally $[25,26]$, which caused great economic loss in the swine industry. There is a high prevalence observed in numerous swine-

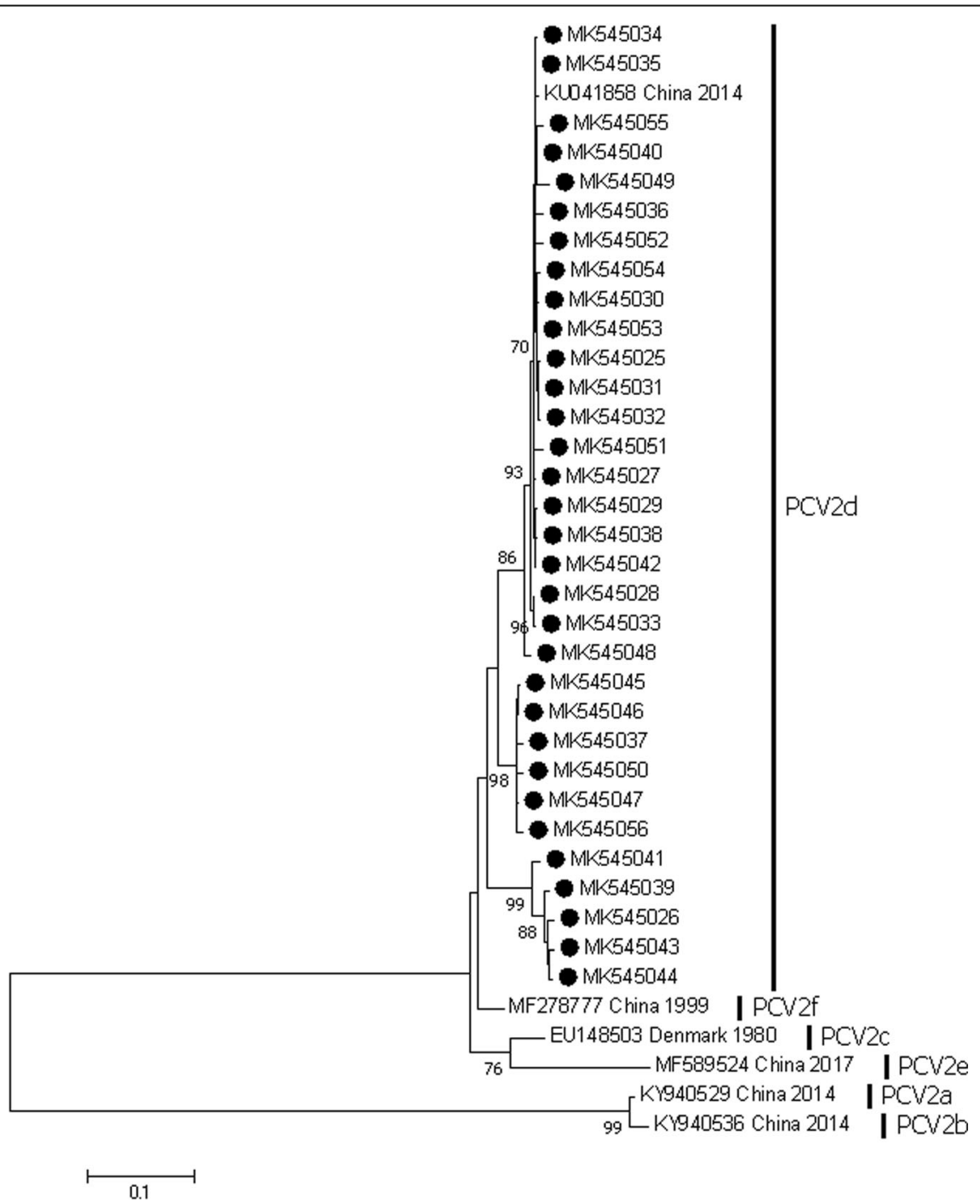

Fig. 1 The phylogenetic analysis based on the cap genes of PCV2. Phylogenetic trees were constructed with the MEGA 7.0.14 software using the neighbor-joining ( $\mathrm{NJ}$ ) method, with the Jukes-cantor model as a nucleotide substitution model. The reliability of the generated trees was determined with 1000 replicates of the data set. Thirty-two isolates and six reference sequences were analyzed 
Table 4 Positive rate of PCV2 and its coinfection rate in different cities in Shandong Province from 2015-2018

\begin{tabular}{|c|c|c|c|c|c|c|}
\hline City & Number of positive samples & Positive rate & PCV2 + PRRSV & PCV2 + PRV & PCV2 + CSFV & PCV2 + PEDV \\
\hline Linyi & 89 & $18.16 \%$ & 28 & 15 & 14 & 2 \\
\hline Tai'an & 61 & $12.45 \%$ & 19 & 28 & 3 & 1 \\
\hline Ji'ning & 44 & $8.98 \%$ & 15 & 11 & 6 & 2 \\
\hline Liaocheng & 41 & $8.37 \%$ & 7 & 10 & 9 & 0 \\
\hline Laiwu & 40 & $8.16 \%$ & 15 & 5 & 7 & 3 \\
\hline Dongying & 36 & $7.35 \%$ & 8 & 4 & 1 & 0 \\
\hline Binzhou & 34 & $6.94 \%$ & 6 & 3 & 5 & 1 \\
\hline Ji'nan & 29 & $5.92 \%$ & 9 & 1 & 3 & 1 \\
\hline Weifang & 29 & $5.92 \%$ & 9 & 2 & 3 & 0 \\
\hline Heze & 26 & $5.31 \%$ & 3 & 1 & 8 & 3 \\
\hline Zibo & 16 & $3.27 \%$ & 6 & 3 & 1 & 2 \\
\hline Dezhou & 12 & $2.45 \%$ & 2 & 2 & 1 & 0 \\
\hline Rizhao & 10 & $2.04 \%$ & 1 & 1 & 2 & 0 \\
\hline Weihai & 7 & $1.43 \%$ & 2 & 0 & 0 & 1 \\
\hline Yantai & 7 & $1.43 \%$ & 0 & 0 & 1 & 0 \\
\hline Zaozhuang & 5 & $1.02 \%$ & 1 & 3 & 0 & 1 \\
\hline Qingdao & 4 & $0.82 \%$ & 0 & 1 & 0 & 0 \\
\hline Total & 490 & & $131 / 490(26.73 \%)$ & $90 / 490(18.37 \%)$ & $64 / 490(13.06 \%)$ & $17 / 490(3.47 \%)$ \\
\hline
\end{tabular}

farming countries. Previous investigations have indicated that the positive rate of PCV2 in swine farms in China was over $50 \%[15,20,27]$. As one of the most vital regions in China regarding breeding food animals, Shandong province raises dense pig population, which suffered PCV2 in recent years. Our study investigated PCV2 seroprevalence, genetic characterization, and its confection rates with other essential swine viral diseases in the field. Results of this study provide useful information on tackling the spread of PCV2 in the province.

Depending on the phylogenetic analysis of cap genes, PCV2 can be divided into five genotypes, defined as PCV2a, PCV2b, PCV2c, PCV2d, and PCV2e [28-30]. Previous studies indicated that PCV2a and PCV2b were the two major genotypes of PCV2 circulating in China with positive rates exceeding 50\% from 2006 to 2007 [20, 31]. Since 2008, while there was an observed decrease of positive rate of PCV2b, positive rates of PCV2d showed an increase up to approximately $50 \%$ were found in samples collected in the field, indicating that PCV2d became the predominant genotype after 2008 [18, 24]. PCV2e contains an additional five amino acid at the Cterminal end resulting in 238 amino acids of ORF2, which has been recently identified as a new genotype [31]. In China, with an exception of PCV2c which was only reported in Denmark [32], other four genotypes are circulating in the field. A genotype shifting from PCV2a and PCV2b to PCV2d in many countries since 2012 [14, $15,18]$. In the present study, PCV2d as a dominant the genotype was highly prevalent in the field in Shandong province in China. Furthermore, several specific motifs were identified, 86 TNKISI91, 129FFPKST134 and 185MRIQTSK192 in PCV2d strains. Additionally, some of the amino acid mutations identified in this study are associated with antibody recognitions and virulence of the PCV2, which may be relevant to the immune escape mechanisms [33].

It is commonly for pigs to be identified as coinfection with different pathogens in the field conditions [14, 17, 34]. Studies in the past demonstrated that pigs can be coinfected by PCV2 with numerous pathogens, such as PRRSV, CSFV, PRV, and PEDV, etc. Previous investigations reported that there was approximately 21.9-52.3\% of coinfection rates of PRRSV and PCV2 [11, 34-36]. The coinfection rate of PCV2 and PRV was shown as $35 \%$ in field samples [37]. Approximately 50\% and 80\% samples collected at sample and farm level were shown as PCV2 and PEDV coinfection [14]. In this study, different patterns of combined infections were tested with the positive rates ranged from 26.73\% (PCV2 + PRRSV) to $3.47 \%$ (PCV2 + PEDV) (Table 4). Our results indicate that there is a high frequency of coinfection of PCV2 and PRRSV in Shandong province. Combined with previous investigations, results in this study indicated that different patterns of dual infections are often seen in intensive swine breeding system in China. Moreover, further discussions on the refinement of animal disease control strategies was driven by the complicated coinfection status shown in the results $[14,17,20,34-36]$. It is therefore of overriding importance to take forceful 


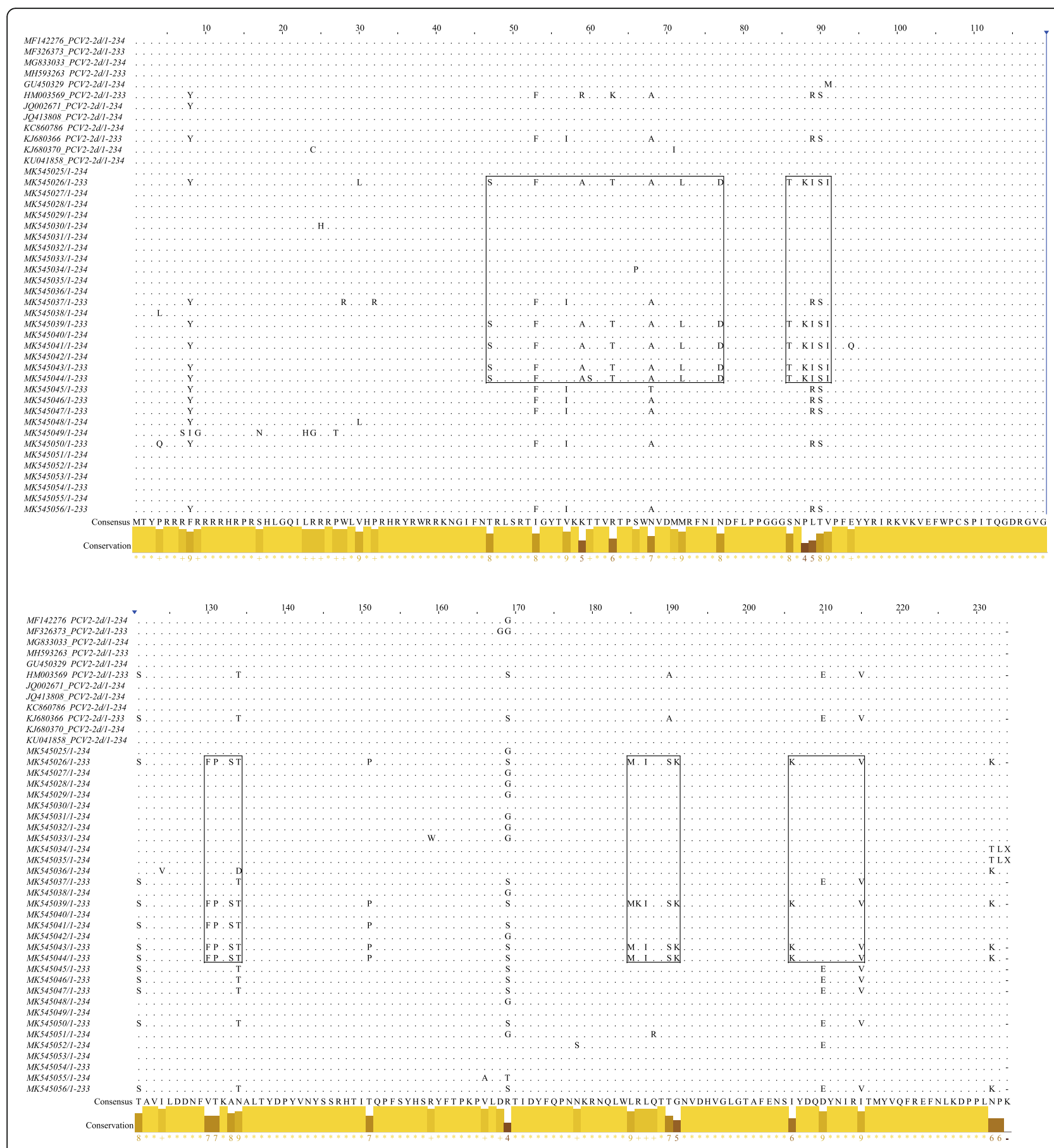

Fig. 2 Amino acid sequence alignment of cap protein of 32 PCV2 isolates. The 32 isolates and 12 reference cap protein were aligned by clustal W method in MEGA6.0 software

measures, such as strengthening biosecurity, monitoring and surveillance, and improving environmental hygiene.

\section{Conclusions}

We investigated the molecular characterization and prevalence of PCV2 as well as its co-infection statues in
Shandong province from 2015 to 2018. Our results clearly reveal that PCV2d, as the dominant strain, is prevailing at high levels in intensive pig farms in the investigated province. Furthermore, we found new mutations which may be related to antibody recognitions and virulence of PCV2 and immune escape mechanisms. It also provided data and insights on co-infection status of 
Table 5 All primers used in this study

\begin{tabular}{llll}
\hline Primer name & Sequences & Annealing Temperature $\left({ }^{\circ} \mathrm{C}\right)$ & Product size(bp) \\
\hline PCV2-F & CCATATGAAATAAATACTGAG & 51 & 785 \\
PCV2-R & CAGCGCACTTCTTTCGTITCAG & 57 & 599 \\
CSFV-F & TRACCAYGCAYATGWCAGAAGTACC & \\
CSFV-R & AGTCGACTTCCCTGGTTCACTTG & 55 & 372 \\
PRRSV-F & GCGGATCCATGCCAAATAACAAC & & 632 \\
PRRSV-R & AGCTCGAGTCATGCTGAGGGTGA & 57 \\
PRV-F & TCCACTCGCAGCTCTTCT & & 552 \\
PRV-R & GCACGTCATCACGAAGGA & 51 & \\
PEDV-F & TTCCCGTTGATGAGGTGAT & & \\
PEDV-R & AAGCATTGACTGAACGACC &
\end{tabular}

PCV2 and other major swine viral diseases, which can improve the understanding from epidemiological perspective and may contribute the prevention and control swine diseases in China.

\section{Methods}

\section{Experimental Protocols}

Serum samples were collected from 277 intensive pig farms ( $\geq 300$ sows) that located in 17 cities in Shandong Province. They were categorized as following groups, including sow, replacement pig, boar, fatting pig, and piglets. By using PCR or RT-PCR, tissue samples were randomly selected from local slaughterhouses to test positive rate of PCV2 and its coinfection rate with PRRSV, PRV, CSFV, and PEDV, respectively.

\section{Serum sample collection and ELISA}

A total number of 6,986 serum samples were collected from 17 cities in Shandong, covering the entire province. Blood collection through the jugular vein and the animal were released. Commercial ELISA kits (MEDIAN Diagnostics, Korea) were used according to the manufacturer's instructions to differentiate the vaccine strain from field strains. The serum sample was diluted 1:100 times, and the detection process was carried out according to the instructions. After the operation, the sample plate was placed at the wavelength of $450 \mathrm{~nm}$ to measure the OD value of each hole. When the OD value of positive control $\geq 0.5$ and the $\mathrm{OD}$ value of negative control $\leq 0.3$, the experiment is established. Standards for negative and positive samples: $S / P$ value $\geq 0.4$ is considered positive; $\mathrm{S} / \mathrm{P}$ values $<0.3$ were considered negative; $0.3 \leq \mathrm{S} / \mathrm{P}$ values $<0.4$ were considered suspicious. $\mathrm{SP}=$ (sample value-negative value) / (positive valuenegative value).

\section{Primer design and virus detection}

One thousand three hundred twenty-five tissue samples, including lymph gland, spleen, and brain samples were collected from several slaughterhouses in Shandong province. All pigs bled to death after electronarcosis. According to the manufacturer's instructions, commercial kits (Takara Biomedical Technology, Beijing, China) were used to extract viral DNA or RNA of the samples. All primers used in this study were summarized in Table 5. Extracted DNA was used as template to detect PRV and PCV2 by PCR. RNA was used to detect PEDV, CSFV and PRRSV by RT-PCR.

The PCR cycle profile and cycling conditions have been described previously [34]. All sequence of primers used and relevant $X$ values refer to annealing temperature are summarized in Table 5. PCR products were subjected to electrophoresis on 1\% agarose gels stained with ethidium bromide and visualized with an ultraviolet light transilluminator. The PCR product is recovered by gel, connected to the $\mathrm{pMD} 18$ - $\mathrm{T}$ vector (Takara Biomedical Technology, Beijing, China), transformed into DH5 $\alpha$ competent cells, and cultured for enrichment. The bacterial liquid identified as positive for the gE gene was sent to Company (Sangon Biotech, Shanghai, China) for sequencing.

\section{Phylogenetic analysis}

The Multiple sequence alignments were conducted by Clustal W of the Megalign program (DNAStar software/Sequence sorting), MEGA 7 (mega software/linearized phylogenetic trees), Bioedit (Bioedit software/ genetics analysis). 17 reference PCV2 genome sequences were obtained from the GenBank database to compare and determine the genotype of the PCV2 isolates.

\section{Abbreviations}

CSV: Classical swine fever virus; PCV2: Porcine circovirus type 2; PEDV: Porcine epidemic diarrhea virus; PRRSV: Porcine reproductive and respiratory syndrome virus; PRV: Pseudorabies virus; SPR: Seroprevalence rate

Acknowledgements

Not applicable. 


\section{Authors' contributions}

Conceptualization, Data curation, Formal analysis, Writing - original draft: ZH, ZM. Investigation: ZM, ZL, FM, HW, LC, YL, QJ. Funding acquisition: SL. Methodology: ZM, ML. Writing - review \& editing: SL, ML. All authors read and approved the final manuscript.

\section{Funding}

Shandong "Double Tops" Program; National Key Research and Development Program of China, Grant/Award Number: 2017YFD0500600. The funding body was solely involved in funding and had no role in the design of the study, the collection, analysis, and interpretation of the data, or in writing the manuscript.

\section{Availability of data and materials}

The datasets generated and analysed during the current study are available in the NCBI repository.

32 isolates sequences:

MK545025: https://www.ncbi.nlm.nih.gov/nuccore/MK545025. MK545026: https://www.ncbi.nlm.nih.gov/nuccore/MK545026. MK545027: https://www.ncbi.nlm.nih.gov/nuccore/MK545027. MK545028: https://www.ncbi.nlm.nih.gov/nuccore/MK545028. MK545029: https://www.ncbi.nlm.nih.gov/nuccore/MK545029. MK545030: https://www.ncbi.nlm.nih.gov/nuccore/MK545030 MK545031: https://www.ncbi.nlm.nih.gov/nuccore/MK545031 MK545032: https://www.ncbi.n/m.nih.gov/nuccore/MK545032. MK545033: https://www.ncbi.nlm.nih.gov/nuccore/MK545033. MK545034: https://www.ncbi.nlm.nih.gov/nuccore/MK545034. MK545035: https://www.ncbi.nlm.nih.gov/nuccore/MK545035. MK545036: https://www.ncbi.n/m.nih.gov/nuccore/MK545036. MK545037: https://www.ncbi.nlm.nih.gov/nuccore/MK545037. MK545038: https://www.ncbi.n/m.nih.gov/nuccore/MK545038. MK545039: https://www.ncbi.nlm.nih.gov/nuccore/MK545039. MK545040: https://www.ncbi.n/m.nih.gov/nuccore/MK545040. MK545041: https://www.ncbi.nlm.nih.gov/nuccore/MK545041. MK545042: https://www.ncbi.nlm.nih.gov/nuccore/MK545042. MK545043: https://www.ncbi.nlm.nih.gov/nuccore/MK545043. MK545044: https://www.ncbi.nlm.nih.gov/nuccore/MK545044. MK545045: https://www.ncbi.nlm.nih.gov/nuccore/MK545045. MK545046: https://www.ncbi.nlm.nih.gov/nuccore/MK545046. MK545047: https://www.ncbi.nlm.nih.gov/nuccore/MK545047. MK545048: https://www.ncbi.nlm.nih.gov/nuccore/MK545048. MK545049: https://www.ncbi.n/m.nih.gov/nuccore/MK545049. MK545050: https://www.ncbi.nlm.nih.gov/nuccore/MK545050 MK545051: https://www.ncbi.n/m.nih.gov/nuccore/MK545051. MK545052: https://www.ncbi.nlm.nih.gov/nuccore/MK545052. MK545053: https://www.ncbi.nlm.nih.gov/nuccore/MK545053. MK545054: https://www.ncbi.nlm.nih.gov/nuccore/MK545054 MK545055: https://www.ncbi.nlm.nih.gov/nuccore/MK545055. MK545056: https://www.ncbi.nlm.nih.gov/nuccore/MK545056. 17 reference sequences:

KU041858: https://www.ncbi.nlm.nih.gov/nuccore/KU041858. MF278777: https://www.ncbi.nlm.nih.gov/nuccore/MF278777. EU148503: https://www.ncbi.nlm.nih.gov/nuccore/EU148503. MF589524: https://www.ncbi.nlm.nih.gov/nuccore/MF589524. KY940529: https://www.ncbi.nlm.nih.gov/nuccore/KY940529. KY940536: https://www.ncbi.nlm.nih.gov/nuccore/KY940536. MF142276: https://www.ncbi.nlm.nih.gov/nuccore/MF142276. MF326373: https://www.ncbi.nlm.nih.gov/nuccore/MF326373. MG833033: https://www.ncbi.nlm.nih.gov/nuccore/MG833033. MH593263: https://www.ncbi.nlm.nih.gov/nuccore/MH593263. GU450329: https://www.ncbi.nlm.nih.gov/nuccore/GU450329. HM003569: https://www.ncbi.nlm.nih.gov/nuccore/HM003569. JQ002671: https://www.ncbi.nlm.nih.gov/nuccore/JQ002671. JQ413808: https://www.ncbi.nlm.nih.gov/nuccore/JQ413808. KC860786: https://www.ncbi.nlm.nih.gov/nuccore/KC860786. KJ680366: https://www.ncbi.n/m.nih.gov/nuccore/KJ680366. KJ680370: https://www.ncbi.nlm.nih.gov/nuccore/KJ680370.

\section{Ethics approval and consent to participate}

The protocol of this study was approved by the Ethic Committee on the animals of Shandong Agricultural University (SDAUA-2015-012).

\section{Consent for publication}

Not applicable.

\section{Competing nterests}

The authors declare that they have no competing interests.

\section{Author details}

${ }^{1}$ College of Animal Science and Veterinary Medicine, Shandong Agricultural University, 271018 Taian, China. 'Laboratory of Zoonoses, Animal Health and Epidemiology Center, 266032 Qingdao, China. ${ }^{3}$ Emergency Centre for the Control of Transboundary Animal Diseases, Food and Agriculture Organization of the United Nations (FAO), 100600 Beijing, China.

Received: 22 May 2020 Accepted: 9 December 2020

Published online: 07 January 2021

\section{References}

1. Tischer I, Gelderblom H, Vettermann W, Koch MJN. A very small porcine virus with circular single-stranded DNA. Nature. 1982;295:64-6.

2. Firth C, Charleston MA, Duffy S, Shapiro B, Holmes ECJJov. Insights into the evolutionary history of an emerging livestock pathogen: porcine circovirus 2. J Virol. 2009;83:12813-21

3. Opriessnig T, Meng XJ, Halbur PG. Porcine circovirus type 2 associated disease: update on current terminology, clinical manifestations, pathogenesis, diagnosis, and intervention strategies. J Vet Diagn Invest. 2007;19:591-615.

4. Mankertz A, Caliskan R, Hattermann K, Hillenbrand B, Kurzendoerfer P, Mueller B, Schmitt C, Steinfeldt T, Finsterbusch T. Molecular biology of Porcine circovirus: analyses of gene expression and viral replication. Vet Microbiol. 2004:98:81-8

5. LV QZ, Guo KK, Zhang YM. Current understanding of genomic DNA of porcine circovirus type 2. Virus Genes. 2014:49:1-10.

6. Ren L, Chen X, Ouyang H. Interactions of porcine circovirus 2 with its hosts. Virus Genes. 2016:52:437-44.

7. Mankertz J, Buhk HJ, Blaess G, Mankertz A. Transcription analysis of porcine circovirus (PCV). Virus Genes. 1998:16:267-76.

8. Cao J, Lin C, Wang H, Wang L, Zhou N, Jin Y, Liao M, Zhou J. Circovirus transport proceeds via direct interaction of the cytoplasmic dynein IC1 subunit with the viral capsid protein. J Virol. 2015;89:2777-91.

9. Olvera A, Cortey M, Segales J. Molecular evolution of porcine circovirus type 2 genomes: phylogeny and clonality. Virology. 2007;357:175-85.

10. Segalés J, Olvera A, Grau-Roma L, Charreyre C, Nauwynck H, Larsen L, Dupont K, McCullough K, Ellis J, Krakowka SJVR. PCV-2 genotype definition and nomenclature. Vet Rec. 2008;162:867-8.

11. Guo LJ, Lu YH, Wei YW, Huang LP, Liu CM. Porcine circovirus type 2 (PCV2): genetic variation and newly emerging genotypes in China. Virol J. 2010;7:273.

12. Jiang CG, Wang G, Tu YB, Liu YG, Wang SJ, Cai XH, An TQ. Genetic analysis of porcine circovirus type 2 in China. Arch Virol. 2017;162:2715-26.

13. Kwon T, Lee DU, Yoo SJ, Je SH, Shin JY, Lyoo YS. Genotypic diversity of porcine circovirus type 2 (PCV2) and genotype shift to PCV2d in Korean pig population. Virus Res. 2017;228:24-9.

14. Guo Z, Ruan H, Qiao S, Deng R, Zhang G. Co-infection status of porcine circoviruses (PCV2 and PCV3) and porcine epidemic diarrhea virus (PEDV) in pigs with watery diarrhea in Henan province, central China. Microb Pathog. 2020;142:104047.

15. Zheng G, Lu Q, Wang F, Xing G, Feng H, Jin Q, Guo Z, Teng M, Hao H, Li D, et al. Phylogenetic analysis of porcine circovirus type 2 (PCV2) between 2015 and 2018 in Henan Province, China. BMC Vet Res. 2020;16:6.

16. Thangthamniyom N, Sangthong P, Poolperm P, Thanantong N, Boonsoongnern A, Hansoongnern P, Semkum P, Petcharat N, Lekcharoensuk P. Genetic diversity of porcine circovirus type 2 (PCV2) in Thailand during 2009-2015. Vet Microbiol. 2017;208:239-46.

17. Chen N, Huang Y, Ye M, Li S, Xiao Y, Cui B, Zhu J. Co-infection status of classical swine fever virus (CSFV), porcine reproductive and respiratory syndrome virus (PRRSV) and porcine circoviruses (PCV2 and PCV3) in eight regions of China from 2016 to 2018. Infect Genet Evol. 2019:68:127-35.

18. Ssemadaali MA, Ilha M, Ramamoorthy S. Genetic diversity of porcine circovirus type 2 and implications for detection and control. Res Vet Sci. 2015;103:179-86. 
19. Jung K, Kim J, Ha Y, Choi C, Chae C. The effects of transplacental porcine circovirus type 2 infection on porcine epidemic diarrhoea virus-induced enteritis in preweaning piglets. Vet J. 2006;171:445-50.

20. Qu T, Li R, Yan M, Luo B, Yang T, Yu X. High prevalence of PCV2d in Hunan province, China: a retrospective analysis of samples collected from 2006 to 2016. Arch Virol. 2018;163:1897-906.

21. Shuai J, Wei W, Li X, Chen N, Zhang Z, Chen X, Fang W. Genetic characterization of porcine circovirus type 2 (PCV2) from pigs in highseroprevalence areas in southeastern China. Virus Genes. 2007;35:619-27.

22. Wang Y, Noll L, Lu N, Porter E, Stoy C, Zheng W, Liu X, Peddireddi L, Niederwerder M, Bai J: Genetic diversity and prevalence of porcine circovirus type 3 (PCV3) and type 2 (PCV2) in the Midwest of the USA during 2016-2018. Transbound Emerg Dis 2019.

23. Xia D, Huang L, Xie Y, Zhang X, Wei Y, Liu D, Zhu H, Bian H, Feng L, Liu C: The prevalence and genetic diversity of porcine circovirus types 2 and 3 in Northeast China from 2015 to 2018. Arch Virol 2019, 164:2435-2449.

24. Karuppannan AK, Opriessnig T. Porcine Circovirus Type 2 (PCV2) Vaccines in the Context of Current Molecular Epidemiology. Viruses 2017, 9.

25. Allan GM, McNeilly F, Kennedy S, Daft B, Clarke EG, Ellis JA, Haines DM, Meehan BM, Adair BM. Isolation of porcine circovirus-like viruses from pigs with a wasting disease in the USA and Europe. J Vet Diagn Invest. 1998;10:3-10

26. Nayar GP, Hamel A, Lin L. Detection and characterization of porcine circovirus associated with postweaning multisystemic wasting syndrome in pigs. Can Vet J. 1997;38:385-6.

27. Sun J, Huang L, Wei Y, Wang Y, Chen D, Du W, Wu H, Liu C. Prevalence of emerging porcine parvoviruses and their co-infections with porcine circovirus type 2 in China. Arch Virol. 2015;160:1339-44.

28. Davies B, Wang X, Dvorak CM, Marthaler D, Murtaugh MP. Diagnostic phylogenetics reveals a new Porcine circovirus 2 cluster. Virus Res. 2016;217:32-7.

29. Liu J, Wei C, Dai A, Lin Z, Fan K, Fan J, Liu J, Luo M, Yang X. Detection of PCV2e strains in Southeast China. PeerJ. 2018:6:e4476.

30. Xiao CT, Halbur PG, Opriessnig T. Global molecular genetic analysis of porcine circovirus type 2 (PCV2) sequences confirms the presence of four main PCV2 genotypes and reveals a rapid increase of PCV2d. J Gen Virol. 2015:96:1830-41.

31. Bao F, Mi S, Luo Q, Guo H, Tu C, Zhu G, Gong W. Retrospective study of porcine circovirus type 2 infection reveals a novel genotype PCV2f. Transbound Emerg Dis. 2018;65:432-40.

32. Yang S, Yin S, Shang Y, Liu B, Yuan L, Zafar Khan MU, Liu X, Cai J. Phylogenetic and genetic variation analyses of porcine circovirus type 2 isolated from China. Transbound Emerg Dis. 2018;65:e383-92.

33. Zhai $S L$, Chen $S N$, Xu ZH, Tang MH, Wang FG, Li XJ, Sun BB, Deng SF, Hu J, Lv DH, et al. Porcine circovirus type 2 in China: an update on and insights to its prevalence and control. Virol J. 2014;11:88

34. Ma ZC, Liu HZF, Meng ZH, Wang FL, Cao HY, Li LL, Jiao Y, Liu QL, Liu SD. MD: Epidemiological investigation of porcine pseudorabies virus and its coinfection rate in Shandong Province in China from 2015 to 2018. J Vet Sci 2020, 21.

35. Ge X, Wang F, Guo X, Yang H. Porcine circovirus type 2 and its associated diseases in China. Virus Res. 2012;164:100-6.

36. Liu JK, Wei CH, Yang XY, Dai AL, Li XH. Multiplex PCR for the simultaneous detection of porcine reproductive and respiratory syndrome virus, classical swine fever virus, and porcine circovirus in pigs. Mol Cell Probes. 2013;27:149-52.

\section{Publisher's Note}

Springer Nature remains neutral with regard to jurisdictional claims in published maps and institutional affiliations.

Ready to submit your research? Choose BMC and benefit from:

- fast, convenient online submission

- thorough peer review by experienced researchers in your field

- rapid publication on acceptance

- support for research data, including large and complex data types

- gold Open Access which fosters wider collaboration and increased citations

- maximum visibility for your research: over $100 \mathrm{M}$ website views per year

At $\mathrm{BMC}$, research is always in progress.

Learn more biomedcentral.com/submissions 